\title{
A construção de uma ferramenta social para promoção da saúde e dos direitos das mulheres ${ }^{1}$
}

\author{
Claudia Mara Pedrosa ${ }^{2}$ \\ Universidade Federal de São Carlos, São Carlos-SP, Brasil
}

\begin{abstract}
Resumo: Este artigo relata a construção de uma estratégia de enfrentamento da violência, na área da saúde, que objetivou auxiliar mulheres em situação de violência e profissionais de saúde a compreender o problema e nele intervir a partir da realidade local. Construiu-se o Guia da mulher: Ações de promoção dos direitos, a partir do diálogo com mulheres de uma comunidade em oficinas participativas. A construção do guia foi norteada pela perspectiva do construcionismo social, que compreende a violência de gênero como fenômeno coletivo. O material tem sido utilizado nos serviços de saúde e distribuído gratuitamente às usuárias do Sistema Único de Saúde.
\end{abstract}

Palavras-chave: serviços de saúde, violência, construcionismo social.

\section{The construction of a social tool to promote women's health and rights}

\begin{abstract}
This article reports the construction of a strategy for coping with violence in the health area. It aimed to help women in situation of violence and health professionals to understand the problem and intervene based on the local reality. The Women's Guide: Actions to promote rights was elaborated based on conversations with women from a community in participative workshops. Its elaboration was oriented by the perspective of the social constructionism, which assumes gender violence as a collective phenomenon. The guide has being used in health services and is freely distributed to the users from the Brazilian Single Health System.
\end{abstract}

Keywords: health care services, violence, social constructionism.

\section{La construcción de un instrumento social para la promoción de la salud y los derechos de la mujer}

\begin{abstract}
Resumen: En este artículo se describe la construcción de una estrategia de enfrentar la violencia en el ámbito de la salud, que tiene por objeto ayudar a las mujeres en situaciones de violencia y los profesionales de la salud en la comprensión del problema y la intervención de la realidad local. En la Guía de la mujer: Acciones para promover los derechos metodología utilizada para el diálogo con las mujeres de la comunidad a través de talleres participativos. La construcción se guía por la perspectiva del construccionismo social, que incluye la violencia de género como un fenómeno colectivo. El material se utiliza en el departamento de salud y se distribuye gratuitamente a las usuarias del Sistema Único de Salude de Brasil.
\end{abstract}

Palabras clave: servicios de salud, violencia, construcción social.

Durante os atendimentos realizados no Serviço de Psicologia da Unidade Básica de Saúde de um pequeno município no interior de São Paulo foram identificados altos índices de violência contra a mulher com importantes sequelas à saúde, cujos impactos se apresentam com frequência como depressão, tentativa de suicídio, distúrbios gastrointestinais, síndrome de dor crônica, distúrbios psicossomáticos, lesões físicas, além de diversas consequências na saúde reprodutiva, como gravidez indesejada, contágio de infecções causadas por doenças sexualmente transmissíveis e relações sexuais forçadas, entre outros agravos. A violência contra a mulher é uma questão complexa que demanda bom vínculo de cuidado, incorporação da perspectiva de gênero na atenção, abordagem multiprofissional e articulação intersetorial para a transformação do grave quadro. Porém, na prática profissional e nos serviços de saúde, ainda impera a dificuldade em abordar tal realidade, e alguns fatores como a predominância

1 Apoio: Fundação MacArthur e Fundo Ângela Borba - Recursos para Mulheres. Este texto foi revisado seguindo Acordo Ortográfico da Língua Portuguesa (1990), em vigor a partir de $1^{\circ}$ de janeiro de 2009.

2 Endereço para correspondência:

Profa. Ms. Cláudia Mara Pedrosa. Rua Guatambu, 575. CEP 14040-160. Ribeirão Preto-SP, Brasil.E-mail: pedrosaclaudia@usp.br do modelo de trabalho centrado na doença, a ausência de discussões sobre os determinantes sociais da saúde, a precária comunicação entre os profissionais do serviço e o desconhecimento da rede de apoio social local contribuem para a manutenção dessa dificuldade.

A formação acadêmica dos profissionais da saúde não oferece, na maioria dos cursos, noções sobre o manejo de casos em que a violência de gênero está presente, lacuna que repercute negativamente na prática profissional e na resolubilidade das ações (Pedrosa, 2003). Para dar visibilidade à violência de gênero no setor da saúde são necessárias mudanças conceituais na prática do trabalho, assim como a criação de uma linguagem comum acerca do olhar sobre violência e gênero.

Diante dessas demandas para o enfrentamento da problemática da violência de gênero, que afeta a saúde e as relações socioeconômicas da população feminina, foi proposta à Secretaria de Saúde a estruturação de ações que promovessem às mulheres melhoria na condição de saúde e no exercício dos direitos e da cidadania. O município em questão apresenta baixo índice de desenvolvimento local e sua economia é sustentada pelo setor sucro-alcooleiro, que emprega a maior parte dos moradores locais, com médias salariais abaixo de um salário mínimo. 
Após a anuência do gestor municipal e do apoio recebido do Programa Gênero Reprodução Ação e Liderança promovido pela Fundação MacArthur e pela Fundação Carlos Chagas, as ações foram divididas em duas etapas: sensibilização e capacitação dos profissionais da saúde para a melhoria da qualidade de assistência às mulheres em situação de violência, e elaboração de um guia, objeto de relato deste trabalho. As atividades foram conduzidas sob minha coordenação e norteadas pelo referencial da Psicologia Social da Saúde, que tem como características a atuação centrada numa perspectiva coletiva e o comprometimento com os direitos sociais e com a cidadania (Spink, 2003).

Para a construção do guia, parti do princípio de que as próprias mulheres do local determinam o que será desenvolvido. Busquei, portanto, conhecer os repertórios acerca da violência de gênero e os dispositivos de cuidados da região. Para tal, foram realizadas Oficinas Participativas com as mulheres da comunidade, valorizando a diversidade e a heterogeneidade local.

\section{Método}

\section{Participantes e procedimentos}

Para conhecer os repertórios de violência entre as mulheres da comunidade, estruturei atividades semanais denominadas "Oficinas sobre saúde", que aconteceram no salão comunitário da cidade e foram divulgadas na rádio comunitária e nos serviços de saúde. Foram realizadas 12 oficinas, com 15 participantes em média, de idade entre 15 e 57 anos. Nos encontros, busquei valorizar o processo de comunicação sobre violência e acesso aos direitos, para a construção de um material dialógico, que contemplasse também, no ato da oficina, a promoção da saúde e da cidadania das participantes. O tempo de duração das oficinas variou entre uma hora e meia e duas horas.

O projeto com as atividades, considerando os itens do protocolo padrão sobre ética em pesquisa e intervenção reconhecidos pelo Conselho Nacional de Saúde, foi submetido aos pareceristas do Comitê de Pesquisa da Fundação MacArthur e à Secretaria de Saúde local, e aprovado por ambos. No início das oficinas foram esclarecidos os objetivos do guia e como os dados seriam usados, sendo enfatizado o caráter voluntário da participação e firmado o compromisso de sigilo e respeito à privacidade e à autonomia. As atividades foram precedidas pela leitura e assinatura do Consentimento Informado.

A perspectiva do construcionismo social norteou a elaboração metodológica, que possibilitou abordar o fenômeno não apenas como experiência individual, mas também como fenômeno coletivo (Spink, 1999). Com base na metodologia participativa que teve sua origem no trabalho de Paulo Freire com a educação popular, utilizei dramatizações, dinâmicas de grupo e recursos como vídeos, fotos, encartes e textos para disparar a discussão acerca da violência. Nas oficinas, utilizamos a cartilha Cidadania também é beleza (Fundo de
Desenvolvimento das Nações Unidas para a Mulher [Unifem], 2001) publicada pelo Fundo de Desenvolvimento das Nações Unidas para a Mulher em parceria com o Centro Feminista de Estudos e Assessoria, Centro de Criação de Imagem Popular e Avon. A cartilha aborda o exercício das leis em relação à lesão dos direitos das mulheres.

A metodologia participativa utilizada permite apreender que é no cotidiano familiar, no trabalho e nas instituições, que as pessoas vão produzindo sentidos sobre sua inserção na sociedade, e com esses conhecimentos vão compondo suas práticas e posicionamentos. Vasconcelos (2001), ao discutir a educação popular e a saúde, ressalta que a valorização do saber popular permite que o participante se sinta "em casa" e mantenha a iniciativa. Assim, a educação popular não dá espaço à passividade usual dos processos pedagógicos tradicionais. Além disso, o autor ressalta que não basta o conteúdo discutido ser revolucionário se o processo de discussão se mantém vertical.

Para a transformação social, o empoderamento das mulheres se estrutura tendo o pesquisador-participante como agente facilitador desse processo, em um movimento de construção coletiva. Oliveira e Carvalho (2007), ao discutir a obra de Paulo Freire, afirmam que uma pessoa se apropria do conhecimento quando é capaz de descobrir a razão de ser das coisas, ao que se segue uma ação transformadora. Assim, tanto o agente facilitador quanto a comunidade constroem juntos, num movimento dialógico de trocas contínuas, significados que levam às transformações das relações sociais, como as superações das desigualdades de gênero.

Nos serviços de saúde, ao trabalhar o reconhecimento da relação desigual de poder, que historicamente tem sido desfavorável às mulheres, é necessário buscar pressupostos metodológicos que auxiliem a pensar e concretizar a inclusão da noção de gênero nas relações sociais e institucionais. A definição de gênero enquanto categoria de análise dos fenômenos históricos e sociais, elaborada em meados dos anos 1980 pela historiadora Joan Scott (1995), trouxe significativa contribuição à compreensão das relações de poder. Para Scott, gênero é um elemento constituinte das relações sociais baseadas nas diferenças percebidas entre os sexos e uma forma primeira de significar as relações de poder. Essa perspectiva compreende o masculino e o feminino como construções sociais importantes nas definições das relações de poder. Assim, as relações de gênero são relações de poder que criam desigualdades, subordinações, posições e valores diferenciados para mulheres e homens numa dada organização social. Tais relações são construídas e vividas no cotidiano, expressando a forma como cada sociedade estabelece os lugares de mulheres e homens, desde o espaço doméstico até a estruturação de políticas públicas.

Portella (2001) ressalta que, ao instituir as políticas públicas de gênero, se assume a questão da desigualdade entre homens e mulheres como problema político e social relevante, que, articulado a outros eixos como raça/etnia, classe social e geração, é estruturante da realidade social e norteia 
projetos políticos institucionais que catalisam o movimento de democratização e igualdade de gênero. Dessa maneira, este trabalho buscou compreender os significados da violência na vida das mulheres a partir das relações de gênero e propôs a desconstrução da ideia de uma mulher universal. Trabalhando na perspectiva de gênero, propõem-se mudanças nas práticas de saúde que visem promover a igualdade entre homens e mulheres e o enfrentamento das situações que impossibilitam o desenvolvimento da autonomia das mulheres e acentuam os agravos à saúde da população feminina.

\section{Análise de dados}

Os relatos apresentados nas oficinas possibilitaram agrupar as experiências pessoais ou histórias de pessoas próximas em diferentes tipos de violência. Na análise dos relatos, os repertórios interpretativos, compreendidos aqui como “dispositivos linguísticos que utilizamos para construir versões das ações, eventos e outros fenômenos que estão a nossa volta" (Spink, 1999), auxiliaram na compreensão da construção social da violência entre as mulheres da comunidade e nortearam as informações para a construção do guia.

Durante as atividades os "casos" relatados eram anotados em papéis afixados nas paredes do salão. No final de cada oficina eram elencados os tipos de violência que apareciam em cada relato e escolhidos os mais instigantes para compor o guia. Os relatos foram assim trabalhados conjuntamente com as mulheres, que auxiliaram na divisão dos diferentes tipos de violência. Para cada história foi criada uma personagem fictícia, com nomes sugeridos pelas participantes, assegurando proteção, respeito e sigilo aos casos verídicos inspiradores.

O material foi digitado, conservando o formato original dos relatos, e enviado a uma advogada, que, como consultora, respondeu às questões jurídicas com base em documentos legais (leis e artigos). O material foi reorganizado, sintetizado e enviado a uma ilustradora. Para adaptação final do texto e arranjo das ilustrações foram realizados quatro encontros, no mesmo formato das Oficinas Participativas, para os quais foram convidadas mulheres que já haviam participado das oficinas anteriores. Houve participação média de oito pessoas, com idade entre 15 e 41 anos. Finalizamos o formato do guia e optamos por seguir o modelo ilustrativo da cartilha que norteou as discussões, que combina textos e desenhos e, assim, torna o material didático.

No final do guia foram mapeados os serviços gratuitos de saúde, assistência social, segurança pública e jurídica que atendem a região. Com o objetivo de verificar a abrangência e o funcionamento por área de atuação, visitei esses locais e conversei com pelo menos um articulador da instituição. No guia, os serviços foram divididos por setores, com endereços, telefones e horários de funcionamento.

\section{Resultados e Discussão}

\section{Histórias e vivências da violência de gênero: o caminho trilhado para visibilidade do direito}

Nas oficinas, as participantes corroboraram a existência de diversas ocorrências de maus-tratos e desigualdades de gênero na comunidade, como as já identificadas no cotidiano dos serviços de saúde. As situações relatadas com maior frequência referiam-se à violência doméstica cometida pelo parceiro ou namorado e ao desconhecimento sobre direitos, como a guarda dos filhos na separação do casal. Os casos de sofrimentos e maus-tratos que surgiam nas discussões eram inúmeros, e sempre havia uma "conhecida" ou vizinha de uma participante do grupo que "se sujeitava" a situações adversas. Inicialmente essas situações de sofrimento não eram identificadas pelo grupo como violência, mas sim como uma "sina" das mulheres, um "carma" do qual não conseguiam se livrar.

Em alguns encontros, os relatos só começavam a aparecer, mesmo que timidamente, quando compartilhávamos os materiais de apoio. Ao explorar quais estratégias e recursos locais as mulheres utilizavam quando vivenciavam situações semelhantes às apresentadas nos materiais consultados, começavam a surgir inúmeros exemplos. As participantes relataram que, quando buscavam auxílio nas situações de violência doméstica, este se dava entre familiares, vizinhos, religiosas, benzedeiras ou amigos. Raramente um serviço público foi citado como espaço de ajuda.

Em suas diferentes categorias, a violência praticada pelo marido ainda é vista como "natural" na comunidade. Ao considerarem uma "sina", como citado acima, as mulheres não encontram saídas para a situação que foi "imposta", como um destino.

Na construção do guia, busquei problematizar essas significações a fim de proporcionar um novo olhar a essa violência, rompendo com o caráter definido de sofrimento como alternativa única. Ao apresentar caminhos pautados pelos direitos legais da cartilha do movimento feminista, buscouse, nas discussões, comparar as estratégias e os recursos que elas conheciam e que faziam parte de sua rede de referência, desconstruindo assim a impossibilidade de transformar as realidades.

Dessa maneira, o guia buscou, por meio das histórias criadas, como apresento a seguir, propor soluções, ampliar a informação e divulgar os recursos públicos como possibilidades de trabalhar a prevenção e a redução das situações de violência na comunidade, promovendo ainda a garantia dos direitos das mulheres.

Quero me separar. Mas, enquanto os papéis estiverem no juiz, meu marido ficará em casa? 
Ele me bate, me empurra, dá socos e pontapés, e ainda por cima fica gritando com as crianças. Ninguém tem sossego; dormimos como se estivéssemos com um monstro em casa. (Sofia)

Neste caso, a mulher deve procurar um advogado, que deverá solicitar ao juiz a separação de corpos e o afastamento do ofensor do lar conjugal. Se o marido estiver violento, como na história de Sofia, ele pode ser afastado de casa, por ordem do juiz. Caso ele retorne, a polícia deve ser comunicada, assim como o juiz.

A permanência nos relacionamentos com violência muitas vezes foi atribuída ao temor, medo e receio de perder a guarda dos filhos e não conseguir sobreviver financeiramente sem a presença do marido. As violências psicológicas e físicas apareciam como práticas frequentes nas relações afetivas com namorados, companheiros e maridos e demonstraram a gravidade da desigualdade e opressão a que as mulheres estão sujeitas.

A maioria das mulheres relatou que saía da casa dos pais quando se casava ou quando "se juntava" com o companheiro, e o retorno, após a separação, nem sempre era aceito e apoiado. A condição econômica das mulheres que participaram das oficinas era muito precária e as deixava numa condição social vulnerável, revelando que as relações de gênero ainda estão estruturadas num modelo patriarcal com dependência financeira. Em seu livro Cenas e queixas, Gregori (1993) discute que, em alguns casos, as mulheres vivenciam a violência para preservar o espaço doméstico como uma prática de adaptação e negociação entre os sexos.

Quando as mulheres desconhecem seus direitos, os maridos, por diversas vezes, utilizam essa "oportunidade" para mantê-las vinculadas à relação, mesmo com sofrimento intenso, configurando-se uma violência psicológica. Nas oficinas, as participantes trouxeram exemplos em que o marido afirmava que, mesmo se a esposa fosse embora, ele não assinaria a separação, deixando-a "vinculada a ele". As mulheres apontavam que esse tipo de separação muitas vezes não acontecia, porque o marido ou companheiro, que já era violento e ameaçador na relação contínua, com trocas afetivas, se tornaria um "fantasma" ainda mais ameaçador após a separação. As mulheres entendiam que, quando o marido não concordava em assinar a separação, não acontecia a anulação do casamento. Assim, a mulher ficaria atrelada a ele perante a sociedade, o que impossibilitaria a reestruturação de sua vida social e afetiva; por isso, ele seria um "fantasma".

Foi possível notar que a escassez de informações ou a reprodução de noções equivocadas sobre direitos das mulheres eram uma constante no grupo. No exemplo anterior, a separação pode ser solicitada por um advogado e, no caso de ameaça, a mulher pode pedir auxílio em serviço de segurança pública tanto para proteção como para abrigamento a ela e aos filhos. No exemplo abaixo, que foi escolhido para ser apresentado no texto do guia, buscou-se contribuir para o estabelecimento de relações mais independentes e autônomas.

Meu marido diz que não vai me dar a separação, que eu posso até sumir da vida dele, mas a separação ele não vai dar. (Ivone)

Quando existe briga entre o casal, como neste caso em que o marido não quer dar a separação, a mulher pode pedir ao advogado que entre com a separação judicial litigiosa, expondo os motivos ao juiz (litígio quer dizer briga).

Problemas com paternidade e pensão alimentícia foram semelhantes aos descritos na cartilha que utilizamos como material de apoio. Em todas as oficinas, foram temas mobilizadores, com múltiplos questionamentos, como os direitos dos filhos de casais que nunca conviveram juntos, a busca por exame de DNA, situação de visitas após a separação, e negação do registro e/ou reconhecimento, como no exemplo:

Estou grávida, quero me separar porque meu marido me agride.

Ele diz que se eu for embora ele não vai assumir o filho! (Lourdes)

Toda mulher pode registrar o filho sozinha e informar no cartório quem é o pai. O cartório enviará ao juiz um documento para investigar essa informação. Se o pai ainda negar, será iniciada a Ação de Investigação de Paternidade. Essa ação é a forma legal de provar que o homem é o pai biológico da criança. $A$ ação deve ser proposta por um advogado. Não tendo recursos para pagar um advogado, pode-se procurar um "do Estado", desde que a renda pessoal seja igual ou inferior a três salários mínimos.

Tive filho de um homem que é casado. Ele diz que meu filho não terá os mesmos direitos que os filhos do seu casamento. (Marta)

Todos os filhos têm os mesmos direitos. São legítimos e têm direito à pensão alimentícia, herança, etc. A pensão alimentícia pode ser paga em dinheiro, ou seja, custear moradia, sustento, educação, etc. O valor da pensão é estipulado pelo juiz, salvo quando os pais fazem acordo em relação à quantia a ser paga. Vale lembrar que o não pagamento da pensão alimentícia incide em cadeia para aquele que deveria pagá-la.

A violência psicológica, tais como as ameaças e as coerções que sugerem muitas vezes riscos à vida da mulher, esteve sempre presente nos relatos das oficinas. As participantes, sensibilizadas pelo assassinato de uma mulher da cidade, que havia sido morta pelo ex-marido, lembraram que, antes da ocorrência do fato, ela havia recebido ameaças frequentes dele. A discussão alertou para a necessidade 
de solicitar medidas protetoras em casos extremos, difundir na comunidade e entre os profissionais da saúde os recursos preventivos que podem ser acessados gratuitamente, além da importância de orientar as mulheres a nunca duvidar de ameaças ou de pistas de que algo perigoso pode vir a acontecer.

Tenho um namorado que é extremamente ciumento. Ele desconfia de tudo que faço e de uns tempos para cá tem feito muitas ameaças, anda com um punhal na cintura e diz que está na minha cola.

Quando chego ao trabalho, ele deixa bilhetes dizendo que sabe tudo o que acontece comigo e que está me esperando em casa... Se eu me atrasar um minuto, vai me buscar para me matar. (Juliana)

Ao discutirmos esse tipo de violência psicológica, em que os homens monitoram e cerceiam a companheira, apareceram colocações sobre "o direito que o homem tem sobre a vida da companheira". O discurso que "homem tem de ser controlador" foi importante para desconstruirmos a opressão de gênero, ressaltando o quanto esse comportamento intenso e ameaçador, que muitas vezes é inserido culturalmente como "direito do homem de mandar na mulher e controlar sua vida", gera importantes sequelas, como sintomas de síndrome do pânico e quadro de ansiedade intenso, prejudicando a saúde mental das mulheres.

Ao elaborarmos as diferentes possibilidades de violência psicológica, como a citada abaixo, pudemos avaliar os riscos e compreender quais saídas teriam sido possíveis para evitar o assassinato da moradora.

\begin{abstract}
Ameaça é crime!
Ameaçar bater, matar, mostrar facas, armas, foices; enviar cartas e bilhetes colocando medo; ou mesmo colocar objetos simbólicos para sugerir sofrimento ou morte, por exemplo, mostrar o preço de um caixão sugerindo que vai matá-la. Se você está em perigo, tem escutado de seu namorado, marido ou companheiro muitas mensagens ameaçadoras, não espere acontecer o pior.

Procure se afastar de quem a ameaça, busque ajuda de seus familiares e vizinhos. Grite por socorro quando perceber que sofre risco de morte. Não permaneça em lugares fechados e distantes. Vá até uma delegacia, faça a ocorrência.

Se alguém estranho lhe fizer ameaça pessoal, procure relatar no boletim de ocorrência todos os detalhes da pessoa, como tipo de cabelo, altura, olhos, cicatriz, cor e roupa.
\end{abstract}

Outros tipos de violência vivenciados em ambientes de trabalho ou em instituições, como serviços de saúde, foram lembrados, ressaltando as desigualdades de gênero e a exclusão social da mulher neles. As participantes relataram que por diversas vezes, para se manter no trabalho ou para garantir a continuidade de um atendimento na saúde, vivenciavam situações de extrema violência, como na assistência ao parto.

Nos serviços de saúde ainda existe um pacto de silêncio ao redor da problemática da violência institucional, demonstrando que o controle social ainda está distante de atingir os objetivos almejados, uma vez que a comunidade não está próxima nem inserida suficientemente para discutir tais ocorrências. Nas oficinas, as participantes trouxeram reflexões pertinentes acerca do funcionamento do serviço de saúde e sua organização, que, se fossem levadas em consideração na política de gestão local, resultariam em importantes avanços na equidade e no acesso aos serviços, ampliando o direito à saúde e à justiça social.

Nas especialidades médicas, a área de Ginecologia e Obstetrícia foi a mais lembrada em experiências traumáticas e abusivas, como a escolhida para ilustrar essa categoria:

No meu parto passei muitas dores e chorei. O médico gritava comigo e dizia bravamente para que eu parasse de exagerar, que na hora de fazer o filho eu não gritei como uma louca... então agora não era para gritar... foi horrível! (Camila)

$O$ desrespeito de um profissional com a mulher durante exames ou procedimentos é considerado violência institucional. Toda mulher tem assegurado por lei, durante as consultas, internações e procedimentos, o direito a um atendimento que respeite seus valores éticos e culturais, e que ofereça confidencialidade a toda e qualquer informação pessoal. $O$ atendimento deverá ser digno, atencioso e respeitoso. A mulher precisa sentir segurança nos procedimentos, ser esclarecida sobre condutas e exames.

A situação relatada é de desrespeito e pode ser notificada pela mulher na própria instituição, hospital ou centro de saúde. Pode ser feito ainda um boletim de ocorrência na delegacia de polícia.

A violência sexual nas relações afetivas foi o tema que apareceu mais timidamente nas oficinas, é preciso ressaltar que ainda existem dificuldades culturais em reconhecer ou abordar o assunto nas relações conjugais. A crença sustentada pela Constituição brasileira, que afirmava que o estupro no casamento não era crime, contribuiu para a legitimação, por muitos anos, da violência sexual nas relações entre parceiros íntimos.

Havia um desconhecimento geral sobre as medidas profiláticas indicadas após a ocorrência da violência sexual. Dada a importância em divulgar as ações preventivas, escolhi enfatizar a emergência da situação e descrevi um caso de estupro explicando a ocorrência e os procedimentos adequados, respaldados pela Constituição federal:

Sofri um estupro. O que faço agora?

Quando acontece a penetração do pênis na vagina 
sem a permissão da mulher, ocorre o estupro. Esse tipo de violência sexual também provoca muitas consequências na vida da mulher, por isso ela precisa de ajuda imediata. A violência sexual pode ocorrer de várias outras formas. Não escolhe vítimas. Acontece no mundo todo e atinge mulheres, homens e crianças de todas as idades, raças, orientações sexuais e classes sociais.

Após a violência sexual, a pessoa deverá ser atendida num posto de saúde para receber os procedimentos de emergência a fim de evitar a contaminação de algumas doenças do agressor, como as sexualmente transmissiveis.

Busca-se evitar, especialmente, a infecção pelo vírus HIV, que provoca a Aids. Caso a mulher tenha ficado grávida do agressor, ela tem o direito, por lei, de não dar continuidade à gravidez. Todas essas informações poderão ser dadas à paciente pelos serviços médico, social ou de psicologia do hospital. Após realizar os procedimentos de emergência, a mulher necessitará ser acompanhada por uma equipe de médicos, psicólogos e assistentes sociais, pois a situação de violência sexual, além dos danos físicos, também deixa várias sequelas sociais e emocionais.

\section{Considerações finais}

A construção do guia com a participação das mulheres possibilitou apreender alguns repertórios acerca da violência de gênero presentes na comunidade, revelando a realidade das mulheres com seus problemas e desafios. Os relatos explicitaram que as ações necessárias para a promoção da saúde, dos direitos das mulheres e para a estruturação da autonomia social dependem também de acesso efetivo a outros setores, como educação, economia e trabalho. Os espaços de cuidado à saúde precisam dar visibilidade à violência, incorporar a perspectiva de gênero nas ações e abrir possibilidades de escuta, auxiliando, assim, na reflexão inicial da situação de vulnerabilidade social a que as mulheres estão expostas. O acolhimento desses casos nos serviços é de fundamental relevância, porém, é preciso dar continuidade ao projeto terapêutico para além do setor e incluir em seu cotidiano de trabalho a comunicação ativa com os demais setores, que complementarão o empoderamento das mulheres.

A prática da intersetorialidade é uma estratégia cujo resultado esperado é a superação da fragmentação das políticas nas várias áreas onde são executadas. Para tanto, é preciso integrar diferentes setores na resolução de problemas. Estamos considerando aqui que saúde é resultante de múltiplas políticas sociais de promoção da qualidade de vida. Quando atuamos dentro da perspectiva da intersetorialidade, consideramos os usuários do Sistema Único de Saúde (SUS) na sua totalidade, em suas necessidades individuais e coletivas, demonstrando que ações resolutivas em saúde requerem necessariamente parcerias com outros setores já citados, como emprego, habitação, educação, trabalho, cultura, segurança alimentar, entre outros.

Na prática do SUS, apesar de importantes políticas de humanização e acolhimento propostas pelo Ministério da Saúde, vivenciamos ainda modelos precários de gestão com escassas e/ou frágeis redes ativas de cuidado para evitar a violência. A organização dos serviços e do modelo de gestão de trabalho verticalizado com rupturas na comunicação intrasserviços, falta de capacitação e atualização profissional e inexistência de um suporte técnico-afetivo aos profissionais impossibilita, em parte, a reprodução de ações emancipatórias que envolvam também a comunidade nas ações de proteção e prevenção da violência.

Dessa maneira, o trabalho aqui relatado buscou seguir as diretrizes do SUS, que enfatizam a importância da intersetorialidade como ideia de rede, que requer articulações, vinculações, ações complementares, participação ativa da comunidade nos programas de saúde, relações horizontais entre parceiros e interdependência de serviços para garantir a integralidade das ações. Castells (2000) nos traz a noção de redes como estruturas abertas que podem expandir infinitamente formando outros novos nós. Entretanto, para integrar uma rede dinâmica, os participantes precisam estabelecer uma relação entre si, com objetivos comuns, compartilhando valores e solidificando a comunicação efetiva. A elaboração do presente trabalho vem instigar, pela prática e cuidado às mulheres em situação de violência, a construção de um objetivo comum a rede de cuidados e a superação dos modelos reducionistas no cotidiano dos serviços.

O guia é um instrumento de orientação sobre a complexa situação da violência contra mulher, espera ampliar o acolhimento das mulheres nos serviços de saúde para o enfrentamento da violência e nortear caminhos para além desses serviços. Dessa maneira, reforçamos que, para enfrentar a violência de gênero, as ações precisam ocorrer nos espaços coletivos, e não na solidão dos serviços de saúde. A rede precisa também ser avaliada e monitorada para identificar rupturas e mudanças no fluxo dos serviços, assim como as orientações sobre direitos precisam ser atualizadas de acordo com as conquistas sociais.

Portanto, o Guia da mulher: Ações de promoção dos direitos surge como uma estratégia que demandará frequente avaliação dialógica com as mulheres e com os serviços da rede de apoio citados, para verificar sua qualidade e a abrangência das ações pensadas.

Sabemos que as ações para o enfrentamento dessas questões ainda são difíceis e desafiadoras, mas os impedimentos precisam ser continuamente desconstruídos, e a violência de gênero precisa estar incorporada às pautas das reuniões e discussões em equipe. Assim, acreditamos que, tendo em mãos uma ferramenta norteadora para lidar com a violência, os profissionais podem dar visibilidade à violência de gênero nas ações de saúde e promover um atendimento integral e potencializador.

A distribuição do guia às usuárias nos serviços de saúde 
pode ser compreendida como um dispositivo para catalisar a reflexão das mulheres sobre a violência em sua vida e impelir o desejo de mudança e autonomia. Reconhecer que a violência não é uma questão natural e que pode ser transformada e eliminada de sua vida, e conhecer quais são seus direitos e as possibilidades de escolha de uma vida livre de opressão e de maus-tratos configuram-se como um caminho para a construção de relações mais justas e igualitárias, e possibilitam novas formas de organização da vida social às mulheres.

\section{Referências}

Castells, M. (2000). A sociedade em rede. São Paulo: Paz e Terra.

Fundo de Desenvolvimento das Nações Unidas para a $\mathrm{Mu}-$ lher [Unifem]. (2001). Cartilha: Cidadania também é beleza. Brasília: Centro Feminista de Estudos.

Gregori, M. F. (1993). Cenas e queixas: Um estudo sobre mulheres, relações violentas e a prática feminista. São Paulo: Paz e Terra.

Oliveira, P. C., \& Carvalho, P. (2007). A intencionalidade da consciência no processo educativo segundo Paulo Freire [Versão eletrônica]. Paideia (Ribeirão Preto), 17, 219230. Recuperado em 27 agosto 2008, de http://www. scielo.br/pdf/paideia/v17n37/a06v17n37.pdf

Pedrosa, C. M. (2003). Mulheres em situação de violência: $O$ discurso dos profissionais de saúde. Dissertação de mestrado não-publicada, Departamento de Psicologia Social, Pontifícia Universidade Católica de São Paulo, São Paulo.

Portella, A. P. (2001). Novas e velhas questões sobre corpo, sexualidade e reprodução. In B. Ávila (Org.), Textos e imagens do feminismo brasileiro: Mulheres construindo a igualdade. Recife: SOS Corpo.

Scott, J. (1995). Gênero: Uma categoria útil de análise histórica. Educação \& Realidade, 20(2), 71-99.

Spink, M. J. P. (1999). Práticas discursivas e produção de sentidos no cotidiano: Aproximações teóricas e metodológicas. São Paulo: Cortez.

Spink, M. J. P. (2003). Psicologia social e saúde: Prática, saberes e sentidos. Petrópolis, RJ: Vozes.

Vasconcelos, E. M. (Org.). (2001). A saúde nas palavras e nos gestos: Reflexões da rede de educação popular e saúde. São Paulo: Hucitec.

Cláudia Mara Pedrosa é Professora Substituta da Universidade Federal de São Carlos, doutoranda pelo Programa de Pós-graduação da Faculdade de Saúde Pública da Universidade de São Paulo, bolsista CNPq. 